\title{
Can exergames be used as an alternative to conventional exercises?
}

\author{
Leonardo Machado da Silva $^{1}$ (D), Fábio Saraiva Flôres ${ }^{2}$ (D), Silvana Correa Matheus ${ }^{3}$ \\ ${ }^{1}$ National Institute of Physical Education of Catalonia, Lleida, Spain; ${ }^{2}$ KinesioLab, Research Unit \\ in Human Movement Analysis, Piaget Institute, Almada, Portugal; ${ }^{3}$ Universidade Federal de \\ Santa Maria, Centro de Educação Física e Desportos, Santa Maria, RS, Brazil.
}

Associate Editor: Cristine L Alberton, Universidade Federal de Pelotas, Pelotas, RS, Brasil.

\begin{abstract}
Aim: The present study aimed to analyze if the exergaming exercise produces the same acute effects as conventional training. Methods: The Nintendo ${ }^{\circledR}$ Wii was chosen as the stimulus for this study. Participants should conduct a physical training session under Exergames Training (ET) and Conventional Training (CT). Both training conditions use two aerobic exercises and six strength exercises, which were always performed in the same sequence. The study group was composed of 30 young adults (16 men and 14 women, mean age of $23.7 \pm 3.7$ years). Results: Our findings showed significant results between pre and post-tests: the heart rate (HR) and the double product (DP) were higher in the post-exercise period, while the systolic blood pressure (SBP) was lower. Further analysis revealed that ET and CT conditions had no significant differences. ET condition showed to present similar results as CT condition to women (regarding HR, diastolic blood pressure - DBP, and DP), and to men (HR, SBP, and DBP). Conclusion: The present research showed that exergaming provides the same acute effects in physiological variables as conventional exercises. Thus, this kind of exercise can be a reliable way to improve the lifestyle of young adults.
\end{abstract}

Keywords Exergaming, exercise, adults, heart rate, blood pressure.

\section{Introduction}

The influence of technology has increased in our society nowadays. Different technologies emerged integrating the physical contexts and persons, providing new opportunities to interact, play, learn, and get knowledge ${ }^{1}$. This influence has been changing the way people interact with each other, how they shop, move, play, and exercise.

The literature shows several understandings about the technology-lifestyle paradigm. On one side, studies argue that mechanical automation, television, computer, and video games are factors that trigger sedentary patterns of lifestyle ${ }^{2-4}$. The time spent in the use of these devices may increase the prevalence of problems related to sedentary behavior, such as increased cardiovascular risks and obesity ${ }^{2-4}$. On the other hand, authors defend that technological advances can modify the relationships that people have with their bodies and with the practice of exercises and physical activities ${ }^{5-7}$. To this last approach the use of digital games, especially Exergames, can enhance the physical fitness of the player. To Jin \& Park $^{8}$ the Exergames are computer games (or video games) that use motion-sensing technology, in other words, technologies that detect users' body movements, allowing players to interact and control different virtual contexts.
The exergaming can substantially impact the user experience and behavior, as they allow the combination of entertainment and movement ${ }^{5}$. Studies indicate that the use of Exergames has shown a positive effect on physical rehabilitation ${ }^{9}$, in humor and engagement ${ }^{10}$, increasing adults energy expenditure ${ }^{11}$, in the cardiovascular response of people with paraplegia ${ }^{12}$, changes in healthrelated behavior ${ }^{13}$, changes in exercise persistence over time $^{14}$, the effects of interactivity and controller use on participants' physiological and psychological outcomes ${ }^{15}$ and, in physical fitness ${ }^{5,16}$. Research also shows that the use of technological devices can help reduce the number of people who abandon activities and exercise ${ }^{17,18}$ and can be used as coping strategies for anxiety disorders pandemic periods ${ }^{19}$. The increase in intrinsic motivation, more significant commitment to activity, fun, pleasure, and feelings of affection allow the engagement with body practice, resulting in repetition of behaviors and maintenance of practice $\mathrm{e}^{20-22}$.

To our knowledge, few studies are found analyzing whether physical training using Exergames is beneficial to the users (or players) and, what the physiological effects they allow in adults ${ }^{21,23}$. The present study aimed to analyze if the practice of exercises with Exergames produces the same acute effects as conventional training sessions. It is expected that training exergaming will produce positive responses in the physiological variables of adults. 


\section{Methods}

\section{Participants}

Fifty-three adults participate in the present research, but only 30 completed all exercises $(\mathrm{M}=25.2 ; \mathrm{SD}=2.4$ years). The study group was conveniently composed of young adults $(\mathrm{n}=30), 16$ men and 14 women, with a mean age of $23.7 \pm 3.7$ years. The percentage of body fat of men was $16.6 \pm 6$ and $25.1 \pm 7$ for women. The selection of participants was voluntary, and the enrollment order was used for the random definition of the type of training (Exergames versus Conventional Training). None of the participants participate in any kind of regular activity program. The recruitment of the participants was carried out through the dissemination of the project on the University's website and social media.

As inclusion criteria, the following aspects were adopted: being in the age group of 18 to 40 years; do not present limiting osteoarticular injuries; ischemic heart disease; symptomatic heart failure; insulin-dependent diabetes mellitus; dyslipidemia and hypertension. People who presented diseases that made it impossible to continue the study; those who did not attend the second training session, 72 hours after the first; those who used controlled psychiatric medication; and those who had a diagnosis of mental illness, were excluded from the study.

The study was submitted and approved by the Universidade Federal de Santa Maria Ethics Committee (31095214.0.0000.5346). All the participants were volunteers and signed the Informed Consent Term.

\section{Procedures}

Participants should conduct a physical training session under two conditions: Exergames Training Session (ET) and Conventional Training Session (CT). Both training conditions use two aerobic exercises and six strength exercises, which were always performed in the same sequence (Aerobic Exercises - Island Cycling and Free Run; Strength Exercises - Rowing Squat, Push up, Lung, Single Leg Extension, Plank, Arm, and Leg Lift). The sequence as mentioned above obeyed the hierarchy of training, proposed by Dantas ${ }^{24}$. The ET condition was performed with the Nintendo® Wii and followed the same guidelines as the $\mathrm{CT}$ condition.

To measure the physiological variables (Heart Rate) the Polar Sensor - FT model ® was used. Blood pressure (BP: Systolic Blood Pressure and Diastolic Blood Pressure) was checked using and sphygmomanometer, before the beginning of the training condition and after each exercise/game, and at the end of the session. The double product (DP) was calculated following the formula (HR x $\mathrm{SBP}=\mathrm{DP}(\mathrm{mmHg} \cdot \mathrm{bpm} / 100)]$.

\section{Exercises}

a) Aerobic Exercises

1. Island Cycling: Simulate the pedaling of the bike. The subject stands on the Wii Balance Board of the Nintendo $(5.5 \mathrm{~cm})$ holding a joystick with both hands (in $90^{\circ}$ flexion of the shoulder joint) and alternately flexes the lower limbs.

2. Free Run: Simulate a stationary run.

b) Strength Exercises

1. Rowing Squat: The subject performs a squat, in which the participant stands up (with the legs at the same width of the shoulders), and a little flexion of the hips and the knees are executed, descending the hip towards the ground.

2. Push up: The subject should position himself in a ventral position, maintaining four supports. The hands should be positioned on the Wii Balance Board.

3. Lung: It is characterized by a deep squat, with the legs arranged in the anteroposterior position and the hands positioned in the neck. The execution occurs in descending towards the ground, maintaining the muscular force in the member that is positioned to the front, one must obey the amplitude of $90^{\circ}$ of the joint of the knee.

4. Plank: Consists of keeping the trunk isometrically in the ventral position, with the elbows positioned on top of the Wii Balance Board, and the tip of the feet, based on the ground, the body must be fully aligned and perpendicular to the ground, and should not raise the hip too much or let it falls too much.

5. Single-Leg Extension: Standing with one-legged support on the Wii Balance Board, hip flexion and extension are performed along with flexion and extension of the shoulder joint opposite the one-leg support. The suspended foot does not touch the ground at any point in the exercise, which requires the motor coordination, balance, and muscular endurance of the practitioner.

6. Arm and Leg Lift: In a four-way position, an extension of one of the lower limbs and extension of one of the opposing upper limbs should be done, which should be holding the joystick.

\section{Experimental design}

Before the exercises, all participants were instructed to perform the exercises at a comfortable (moderate) intensity and to complete all exercises ${ }^{25}$. Also, participants were asked to perform the movements correctly and safely.

The subjects remained seated for five minutes, without external interference and major movements. In the 
resting phase and before the start of the activities, the subjects' HR and BP were monitored.

Both conditions began to perform the data collection with the aerobic exercises. At the end of each exercise, HR and BP were monitored. At the end of the last exercise, the subject remained seated for five minutes, following the same orientations of the resting phase. After five minutes, $\mathrm{HR}$ and BP were monitored. The exercises, in both groups, were 50 minutes long. No feedback was provided to the participants during the tests.

\section{Data analysis}

The Kolmogorov-Smirnov test was used to verify the normality of the data. Descriptive statistics were used with mean and standard deviation for data characterization. Four $2 \times 2$ ANOVAs were performed to analyze the effects of exercise conditions during pre and post-tests, and their interaction for each dependent variable (physiological variables). In all analyses, the Alpha level for significance was set at .05. The Software Statistical Package for Social Sciences TM (SPSS 25.0) was used.

\section{Results}

The results showed that the anthropometric characteristics of the participants are at healthy levels (Men$\mathrm{BMI}=22.7 \pm 2.4 ; \% \mathrm{BF}=25.1 \pm 7.0$; Women-BMI $=24$ $\pm 2.5 ; \% \mathrm{BF}=16.6 \pm 6.0)^{26}$. Table 1 shows the descriptive values of the two exercise conditions and the pre and posttest. Additionally, the ANOVAs results and main effects were presented in Table 1 .

The four overall results of the ANOVAs (see Figure 1) computed with exercise conditions and the physiological variables, do not showed statistical differences. Moreover, the ET and CT conditions present similar results: HR (exercise condition: $\mathrm{F}(1,116)=0,509$, $p<0.47$ ); SBP (exercise condition: $\mathrm{F}(1,116)=0,037$, $p=0.84$ ); DBP (exercise condition: $\mathrm{F}(1,116)=0,594$, $p=0.44$ ); and DP (exercise condition: $\mathrm{F}(1,116)=1,446$, $p=0.23$ ). Results for pre and post-test present significant differences in all physiological variables: HR (pre- and post- test: $\mathrm{F}(1,116)=22.245, p<0.05)$; SBP (pre- and post- test: $\mathrm{F}(1,116)=4,462, \mathrm{p}=0.03$ ); DBP (pre- and post- test: $\mathrm{F}(1,116)=3,931, p<0.05)$; and DP (pre- and post- test: $\mathrm{F}(1,116)=20,224, p<0.05)$. Additionally, there was no interaction effect between the exercise conditions and pre and post-tests: $\mathrm{HR}-\mathrm{F}(1,116)=3,239$, $p=0.07) ; \mathrm{SBP}-\mathrm{F}(1,116)=, 013, p=0.90) ; \mathrm{DBP}-\mathrm{F}$ $(1,116)=, 303, p=0.58)$; and $\mathrm{DP}-\mathrm{F}(1,116)=, 405$, $p=0.52)$.

\section{Discussion}

The present study aimed to compare the acute effects caused by exercises in exergames training and conventional training session on healthy adults. The primary hypothesis of the study was confirmed. The ET condition produced positive responses in physiological variables in adults comparing pre and post-tests. Also, the acute results showed that the ET condition could be so effective as the $\mathrm{CT}$ condition.

Comparing the two conditions of training, our results indicate that both conditions had an acute effect on the analyzed variables. Table 1 shows the means and standard deviation for all physiological variables. The literature shows that HR and DP variables are increased when the subject is performing a physical exercise ${ }^{27,28}$. In the same way, SBP and DBP presented a decrease in their values $^{27,28}$. Thus, as expected, similar results in both conditions were found in the present research.

Table 1 - Group characterization with mean, standard deviation, and test values.

\begin{tabular}{|c|c|c|c|c|c|c|c|}
\hline & \multicolumn{2}{|c|}{ Exergames condition } & \multicolumn{2}{|c|}{ Conventional condition } & \multirow[t]{2}{*}{ Repeated ANOVA } & \multirow[t]{2}{*}{$\eta^{2}$} & \multirow[t]{2}{*}{ Observed power } \\
\hline & Pre & Post & Pre & Post & & & \\
\hline & & & & & Fcondition $(1,116)=0,509 ; p=0.477$ & .004 & .109 \\
\hline \multirow[t]{3}{*}{ HR } & $71.33 \pm 10.24$ & $85.33 \pm 11.41$ & $73.67 \pm 11.00$ & $79.93 \pm 14.07$ & Fpre-post $(1,116)=22,245 ; p=0.000$ & .161 & .997 \\
\hline & & & & & Fcondition*pre-post $(1,116)=3,239 ; p=0.075$ & .075 & .431 \\
\hline & & & & & Fcondition $(1,116)=0,037 ; p=0.848$ & .000 & .054 \\
\hline \multirow[t]{3}{*}{ SBP } & $111.17 \pm 12.15$ & $106.33 \pm 10.98$ & $110.50 \pm 11.01$ & $106.17 \pm 13.24$ & Fpre-post $(1,116)=4,462 ; p=0.037$ & .037 & .554 \\
\hline & & & & & Fcondition*pre-post $(1,116)=0,013 ; p=0.908$ & .908 & .051 \\
\hline & & & & & Fcondition $(1,116)=0,594 ; p=0.442$ & .005 & .119 \\
\hline \multirow[t]{3}{*}{ DBP } & $73.83 \pm 7.62$ & $70.00 \pm 8.30$ & $74.17 \pm 8.31$ & $72.00 \pm 8.87$ & Fpre-post $(1,116)=3,931 ; p=0.050$ & .033 & .503 \\
\hline & & & & & Fcondition*pre-post $(1,116)=0,303 ; p=0.583$ & .583 & .085 \\
\hline & & & & & Fcondition $(1,116)=1,446 ; p=0.232$ & .012 & .222 \\
\hline \multirow[t]{2}{*}{$\mathrm{DP}$} & $79.50 \pm 15.75$ & $90.84 \pm 15.77$ & $81.16 \pm 13.32$ & $96.25 \pm 19.04$ & Fpre-post $(1,116)=20,224 ; p=0.000$ & .148 & .994 \\
\hline & & & & & Fcondition*pre-post $(1,116)=0,405 ; p=0.526$ & .526 & .097 \\
\hline
\end{tabular}

Legend: HR: Heart Rate; SBP: Systolic Blood Pressure; DBP: Diastolic Blood Pressure; DP: Double Product. 


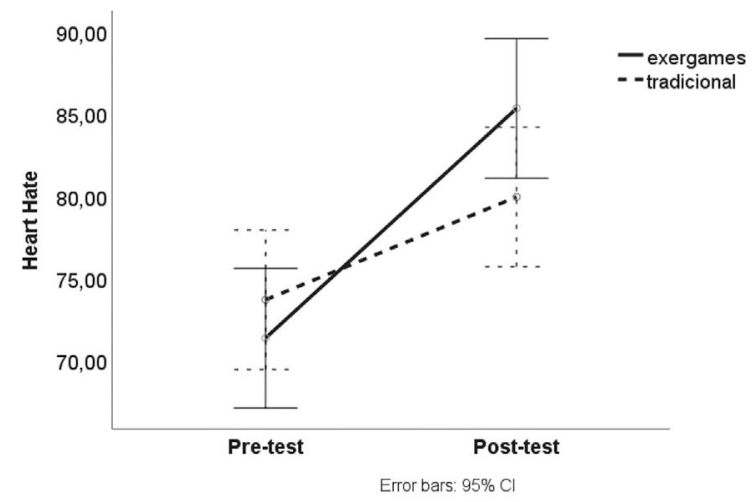

(A) Heart Rate

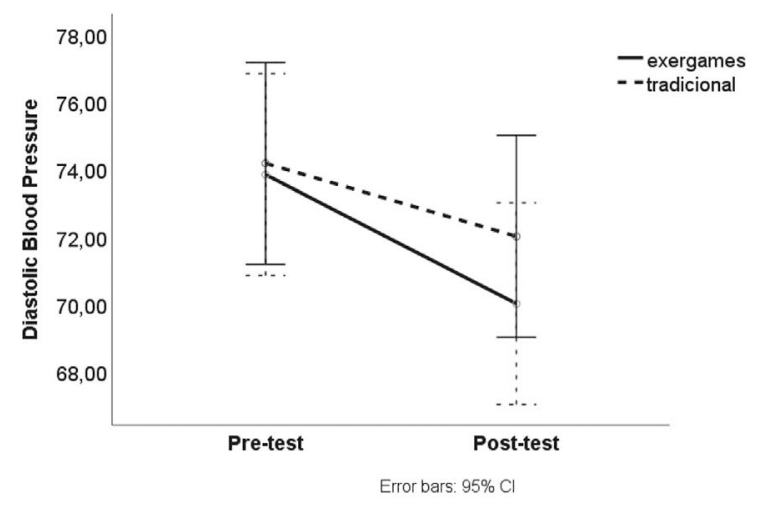

(C) Diastolic Blood Pressure

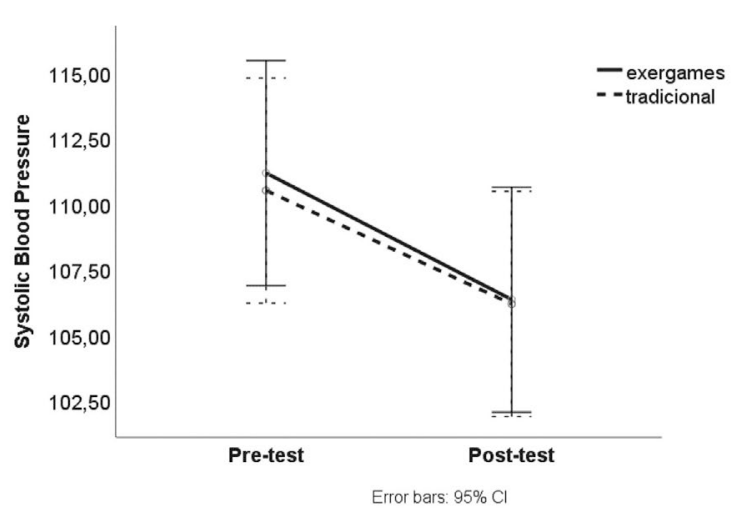

(B) Systolic Blood Pressure

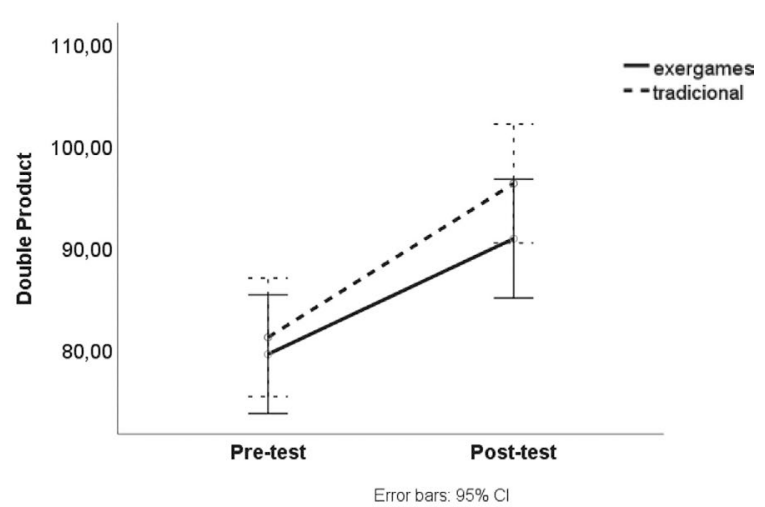

(D) Double Product

Figure 1 - Mean for dependent variables by exercise condition in the pre and post-test.

Our findings showed that ET condition and CT condition might have similar results on physiological variables in healthy adults. In an extensive literature review, Mohd Jai and colleagues ${ }^{29}$ suggest that exergames can produce intensity-adequate physical activity among younger adults. Besides, the exergames are beneficial for cardiometabolic improvements and may be employed as an effective exercise tool to increase energy expenditure and physical activity level in young adults. Wiederhold et al. ${ }^{30}$ also showed that exergames using augmented reality effectively contribute to exercise programs.

Using the Nintendo Wii Fit $®$ to analyze HR with moderate intensity, Douris, McDonald, Vespi, Kelley, \& Herman $^{31}$ found similar results compared to the present research. The authors compare physiologic responses of college students using exergames and an equal duration of moderate-intensity brisk walking. Participants' rating of perceived exertion when playing Wii Fit was significantly greater when compared with brisk walking on the treadmill. Also, the results showed that college students achieve higher intensities during exercises with the Wii Fit when compared to the conventional training session. Besides, the manuscript conclusion was that exercises using the Wii Fit may act as an alternative exercise to the traditional aerobic exercise. These findings provide evi- dence that exergames can help to maintain a healthier and active lifestyle. Additionally, research has shown ${ }^{32}$ that exergames can be used as coping situations during pandemic situations, and appears to be an enjoyable easy-touse tool for reducing social isolation, as well as an interesting mode of home-based exercise for tackling anxiety disorders and sedentary behavior.

All the data provided, as well as the results, showed that exergaming exercises can be used as an important tool in maintaining the health of young adults. The present study shows that young people with greater technology contact can present greater ease in the use of active video games. To summarize, our main findings showed that (1) ET condition produced positive responses in physiological variables, like the $\mathrm{CT}$; and (2) no differences were found between the ET and CT conditions, showing that ET could be used as an important instrument to promote a healthy lifestyle. Thus, our results corroborate the literature, showing the importance of exergaming training, which is an important new way to engage people in training.

Despite the interesting findings, our research presents some limitations. First, we believe that a bigger sample would strengthen our findings. As a second limitation, we do not know the relationship between acute and longterm effects, so further research should try to understand 
this important issue. Also, sex differences have not been assessed. Finally, since the primary aim of the present research was to analyze the acute effects in two different conditions during exercise, doubt remains, could more practice sections result in different behavior?

\section{Conclusions}

Nowadays young adults move less than recommended. The use of new ways of moving around, using video games or active technological devices, seems to be a way to be more explored and studied. Thus, the present research showed that exergaming provides similar benefits in physiological variables than conventional training sessions. Improve the practice of alternative ways of movement, using exergames, is a reliable way to improve the lifestyle of young adults. It is important to note that despite the positive acute effects of the practice with exergames, this can be an ineffective strategy when there is no guidance from physical education professionals because the practice with exergames without guidance can generate a long-term injury and will not present any kind of physiological benefit. Finally, Physical Education professionals and/or Personal Trainers should pay close attention to the new forms of exercise, which can increase physical activity in this population.

\section{References}

1. Schlemmer E. Gamificação em espaços de convivência híbridos e multimodais: design e cognição em discussão. Rev da FAEEBA - Educ e Contemp [Internet]. 2014 [cited 2019 Aug 19];23(2):73-89. Available from: http://www. revistas.uneb.br/index.php/faeeba/article/view/1029

2. Baldissera V, Carvalho M, Pelloso S. Adesão ao tratamento não-farmacológico entre hipertensos de um centro de saúde escola. Rev Gaúcha Enferm [Internet]. 2009 [cited 2019 Aug 19];30(1):27-32. Available from: https://www.seer. ufrgs.br/RevistaGauchadeEnfermagem/article/view/5521

3. Hallal P, Andersen L, Bull F, Guthold R, Haskell W, Ekelund $U$, et al. Global physical activity levels: Surveillance progress, pitfalls, and prospects. Lancet [Internet]. 2012;380 (9838):247-57. Available from: http://dx.doi.org/10.1016/ S0140-6736(12)60646-1

4. Vaghetti C, Botelho S. Ambientes virtuais de aprendizagem na educação física: uma revisão sobre a utilização de Exergames. Ciências \& Cognição [Internet]. 2010 [cited 2019 Aug 19];15(1):76-88. Available from: http://cienciasecogni cao.org/revista/index.php/cec/article/view/292

5. Huang HC, Wong MK, Lu J, Huang WF, Teng CI. Can using exergames improve physical fitness? A 12-week randomized controlled trial. Comput Human Behav. 2017;70:310-6.

6. McCallum S. Gamification and serious games for personalized health. Stud Health Technol Inform. 2012;177:85-96.

7. Staiano A, Calvert S. Exergames for Physical Education Courses: Physical, Social, and Cognitive Benefits. Child Dev Perspect [Internet]. 2011 Jun [cited 2019 Aug 19];5
(2):93-8. Available from: http://doi.wiley.com/10.1111/ j.1750-8606.2011.00162.x

8. Jin SAA, Park N. Parasocial interaction with my avatar: Effects of interdependent self-construal and the mediating role of self-presence in an avatar-based console game, Wii. Cyberpsychology Behav. 2009;12(6):723-7.

9. Taylor MJD, Griffin M. The use of gaming technology for rehabilitation in people with multiple sclerosis. Mult Scler J. 2015;21(4):355-71.

10. Song H, Kim J, Tenzek KE, Lee KM. The effects of competition and competitiveness upon intrinsic motivation in exergames. Comput Human Behav [Internet]. 2013;29 (4):1702-8. Available from: http://dx.doi.org/10.1016/j. chb.2013.01.042

11. Miyachi M, Yamamoto K, Ohkawara K, Tanaka S. METs in adults while playing active video games: A metabolic chamber study. Med Sci Sports Exerc. 2010;42 (6):1149-53.

12. Roopchand-Martin S, Nelson G, Gordon C. Can persons with paraplegia obtain training heart rates when boxing on the Nintendo Wii? New Zeal J Physiother [Internet]. 2014 [cited 2019 Aug 19];42(1):28-32. Available from: http:// search.proquest.com/openview/a3c78485b7be2e47823 $\mathrm{d} 49$ aaac70c9f1/1?pq-origsite $=$ gscholar $\& \mathrm{cbl}=136203$

13. Kim SY, Prestopnik N, Biocca FA. Body in the interactive game: How interface embodiment affects physical activity and health behavior change. Comput Human Behav [Internet]. 2014;36:376-84. Available from: http://dx.doi.org/ 10.1016/j.chb.2014.03.067

14. Max EJ, Samendinger S, Winn B, Kerr NL, Pfeiffer KA, Feltz DL. Enhancing Aerobic Exercise with a Novel Virtual Exercise Buddy Based on the Köhler Effect. Games Health J. 2016;5(4):252-7.

15. Lin JH. "Just Dance": The Effects of Exergame Feedback and Controller Use on Physical Activity and Psychological Outcomes. Games Health J. 2015;4(3):183-9.

16. Purath J, Keller CS, McPherson S, Ainsworth B. A randomized controlled trial of an office-based physical activity and physical fitness intervention for older adults. Geriatr Nurs (Minneap) [Internet]. 2013;34(3):204-11. Available from: http://dx.doi.org/10.1016/j.gerinurse.2013.02.012

17. Anderson CB. When more is better: Number of motives and reasons for quitting as correlates of physical activity in women. Health Educ Res. 2003;18(5):525-37.

18. Ebben W, Brudzynski L. Motivations and barriers to exercise among college students. J Exerc Physiol Online [Internet]. 2008;11(5). Available from: https://www.asep.org/ asep/asep/EbbenJEPonlineOctober2008.pdf

19. Viana R, Lira A. Exergames as Coping Strategies for Anxiety Disorders During the COVID-19 Quarantine Period. Games Health J. 2020;9(3):1-3.

20. Ekkekakis P. Let Them Roam Free? Sport Med. 2009;39 (10):857-88.

21. Graves L, Ridgers N, Williams K, Stratton G, Atkinson G, Cable N. The physiological cost and enjoyment of Wii fit in adolescents, young adults, and older adults. J Phys Act Heal [Internet]. 2010;7(3):393-401. Available from: http://www. embase.com/search/results?subaction=viewrecord \& fro $\mathrm{m}=$ export\&id=L358749607\%0Ahttp://hk.humankinetics. com/eJournalMedia/pdfs/18056.pdf 
22. Motl RW, Dishman RK, Saunders R, Dowda M, Felton G, Pate RR. Measuring enjoyment of physical activity in adolescent girls. Am J Prev Med. 2001;21(2):110-7.

23. Staiano AE, Calvert SL. The promise of exergames as tools to measure physical health. Entertain Comput [Internet]. 2011;2(1):17-21. Available from: http://dx.doi.org/ 10.1016/j.entcom.2011.03.008

24. Dantas EHM. Periodização do treinamento. A prática da Prep física. 2003;6.

25. Borg G. Borg's perceived exertion and pain scales. 1998; Available from: https://psycnet.apa.org/PsycINFO/199807179-000

26. Foss M, Keteyian S. Fox: bases fisiológicas do exercício e do esporte. 2000.

27. Lewis SF, Taylor WF, Graham RM, Pettinger WA, Schutte JE, Blomqvist CG. Cardiovascular responses to exercise as functions of absolute and relative work load. J Appl Physiol [Internet]. 1983 May [cited 2019 Aug 19];54(5):1314-23. Available from: http://www.physiology.org/doi/10.1152/ jappl.1983.54.5.1314

28. Stach T, Graham TCN, Yim J, Rhodes RE. Heart rate control of exercise video games. Proc - Graph Interface. 2009; $125-32$.

29. Mohd Jai N, Mat Rosly M, Abd Razak N. Physiological Responses of Exergaming Boxing in Adults: A Systematic Review and Meta-Analysis. Games Health J. 2020;10(2).

30. Wiederhold MD, Crisci M, Patel V, Nonaka M, Wiederhold BK. Physiological monitoring during augmented reality exercise confirms advantages to health and well-being. Cyberpsychology, Behav Soc Netw. 2019;22(2):122-6.

31. Douris P, McDonald B, Vespi F, Kelley N, Herman L. Comparison between Nintendo Wii Fit aerobics and traditional aerobic exercise in sedentary young adults. journals.lww. com [Internet]. 2012 [cited 2019 Aug 19];26(4):1052-7. Available from: https://journals.lww.com/nsca-jscr/fulltext/ 2012/04000/Comparison_Between_Nintendo_Wii_Fit_Aer obics_and.24.aspx

32. Viana R, De Lira C, Lira A. Exergames as Coping Strategies for Anxiety Disorders during the COVID-19 Quarantine Period. Games Health J. 2020;9(3):147-9.

\section{Corresponding Author}

Fábio Saraiva Flôres, Avenida Jorge Peixinho, nº 302805 059 Almada, Portugal.

E-mail: fabio.flores@almada.ipiaget.pt.

Manuscript received on October 26, 2020

Manuscript accepted on February 18, 2021

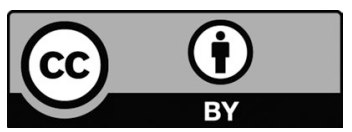

Motriz. The Journal of Physical Education. UNESP. Rio Claro, SP, Brazil - eISSN: 1980-6574 - under a license Creative Commons - Version 4.0 